ERRATUM

\title{
A prospective study of sex steroids, sex hormone-binding globulin, and non-vertebral fractures in women and men: the Tromso Study
}

Åshild Bjørnerem, Luai Awad Ahmed, Ragnar Martin Joakimsen, Gro K Rosvold Berntsen, Vinjar Fønnebø, Lone Jørgensen, Pål Øian, Ego Seeman and Bjørn Straume

The authors apologise for errors in the results reported in their above titled article published in the European Journal of Endocrinology 2007 157 119-125.

Due to a technical error, a number of fractures were not included in the database. In the cohort of 2750 participants, a total of 487 suffered a non-vertebral fracture (not 386 as stated in the article), and the incidence was 30.0 in women and 11.8 in men per 1000 person-years, respectively.

The main results were unchanged after re-analysis and no significant association was present between sex steroids and risk of non-vertebral fractures after adjustment for age in both sexes. Each 1 S.D. higher SHBG increased the risk of non-vertebral fracture by about $20 \%$ in women (HR 1.15; $95 \%$ CI 1.03-1.29) and men (HR 1.18; 95\% CI 0.99-1.41) after adjustment for age, height, weight, smoking and physical activity. After adjustment for BMD, the increased risk was attenuated and no longer statistical significant in women (HR 1.07; 95\% CI 0.96-1.21) and men (HR 1.12; 95\% CI $0.94-1.34)$ respectively.

European Journal of Endocrinology 164445 